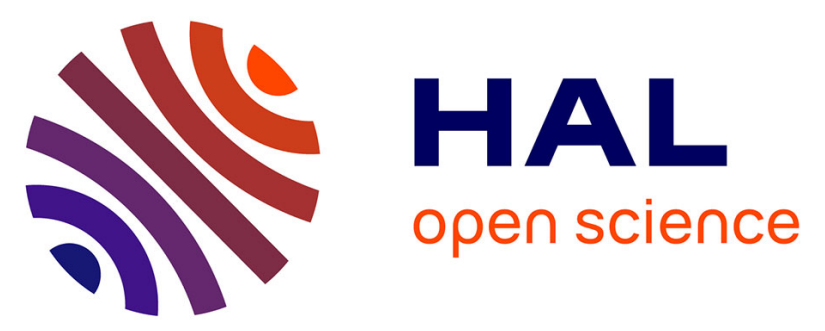

\title{
Purification of organic acids by chromatography with strong anionic resins: Investigation of uptake mechanisms
}

Julien Lemaire, Claire-Line Blanc, Florence Lutin, Marc-André Theoleyre, Moncef Stambouli, Dominique Pareau

\section{To cite this version:}

Julien Lemaire, Claire-Line Blanc, Florence Lutin, Marc-André Theoleyre, Moncef Stambouli, et al.. Purification of organic acids by chromatography with strong anionic resins: Investigation of uptake mechanisms. Journal of Chromatography A, 2016, 1458, pp.63-69. 10.1016/j.chroma.2016.06.057 . hal-01363370

\section{HAL Id: hal-01363370 \\ https://hal.science/hal-01363370}

Submitted on 9 Nov 2016

HAL is a multi-disciplinary open access archive for the deposit and dissemination of scientific research documents, whether they are published or not. The documents may come from teaching and research institutions in France or abroad, or from public or private research centers.
L'archive ouverte pluridisciplinaire HAL, est destinée au dépôt et à la diffusion de documents scientifiques de niveau recherche, publiés ou non, émanant des établissements d'enseignement et de recherche français ou étrangers, des laboratoires publics ou privés. 
9

10 Julien Lemaire ${ }^{\mathrm{a}^{*}}$, Claire-Line Blanc ${ }^{\mathrm{a}, \mathrm{b}}$, Florence Lutin $^{\mathrm{b}}$, Marc-André Theoleyre ${ }^{\mathrm{a}}$,

11 MoncefStambouli ${ }^{\mathrm{a}}$, Dominique Pareau $^{\mathrm{a}}$

a LGPM, CentraleSupélec, Université Paris-Saclay, SFR Condorcet FR CNRS 3417, Centre Européen

13 de Biotechnologie et de Bioéconomie (CEBB), 3 rue des Rouges Terres 51110 Pomacle, France

$14{ }^{b}$ Eurodia Industrie, ZAC Saint Martin, Impasse Saint Martin, 84120 Pertuis, France

15

16 * Corresponding author.

17 Present address: CentraleSupélec, CEBB, 3 rue des Rouges Terres 51110 Pomacle,

18 France.

19 Tel.: +33(0) 352620502 .

20 Email address: julien.lemaire@centralesupelec.fr 
3 Bio-based organic acids are promising renewable carbon sources for the chemical

4 industry.However energy-consuming purification processes are used, like distillation or

5 crystallization, to reach high purities required in some applications. That is why preparative

6 chromatography was studied as an alternative separation technique. In a previous work

7 dealing with the purification of lactic, succinic and citric acids, theLangmuir model was

8 insufficient to explain the elution profiles obtained with a strong anionic resin.

9 Consequentlythe Langmuir model was coupled with a usual ion-exchange model to take 10 into account the retention of their conjugate bases $(<2 \%)$, which are commonly neglected at 11 low $\mathrm{pH}(<1.5)$. Elution simulationswith both uptake mechanisms fitted very well with experimental pulse tests. Only two parameters were optimized (equilibrium constant of acid uptake and ion-exchange selectivity coefficient of conjugate base)and their value were coherent with experimental and resin suppliers' data.

15 These results confirmed that the singular tailing and apparent delay observed with 16 succinic and citric acids can be explained by the high affinity of succinate and citrate for resin

17 cationic sites. Themodel was implemented in a preparative chromatography simulation program in order tooptimize operating parameters of our pilot-scale ISMBunit (Improved

19 Simulated Moving Bed). The comparison with experimental ISMB profiles was conclusive. 
1 Keywords:chromatography; modelling;anionic resin; organic acid;sustainable processing.

2

3 Highlights

4 - Uptake mechanisms of organic acids with strong anionic resin were investigated.

5 - Langmuir model coupled with ion-exchange model fitted with experimental data.

6 - Singular peak tailing and delay were better explained, particularly for citric acid.

7 - Retention of someorganic acidsin the dissociated form cannot be neglected. 


\section{Introduction}

In the frame of sustainable development, biomass valorization as a renewable carbon source for the chemical industry is growing. Indeed, fossil resources are running out in the medium to long term. Moreover carbon balances have to be improved so as to reduce the $\mathrm{CO}_{2}$ level in the atmosphere, whose rapid rise is linked to global warming. In the famous report of the Pacific Northwest National Laboratory (PNNL) and the National Renewable Energy Laboratory (NREL)[1], bio-based organic acids are identified as very promising sources of renewable carbon. Many compounds can be produced from these moleculesinthe chemical industry, particularly inthe polymer industry. Up to now, the production of bio-based organic acids keeps small because they are stilluncompetitive compared to the corresponding petroleum-derived products[2]. That is why the reduction of their production cost is a major concern of the chemical industry.

Bio-based organic acids are usually produced by microbial fermentation for the food industry but further purification techniques are required for others applications which need a much higher purity, particularly polymer synthesis. Currently, distillation [3-4], esterification [5-7]and crystallization [8]are commonly used to reach very high purities (>99.5\%)[9]. However, these techniques are energy-consuming and give quite low recovery rates.Preparative chromatography is a promising solution for downstream processes because its energy, chemical and water consumptions are generally quite lower and consequently effluent volumes too. Initially developed for extraction and purification of complex vegetal mixtures [10], this separation method is spreading in different fields: biotechnology [11-12], pharmaceutic[13-14] and the sugar industry [15], for instance. Indeed, the same separation quality may be reached with better yields, lower costs and impacts on the environment.However, for several years now, the state of the world economy has not been favorable to industrial investments for theimprovement of downstream purification processes. Moreover, chromatography needs to prove itselffor high purity application (> $99.5 \%)$ at the industrial scale. 
In the frame of organic acids purification in fermentation broths, chromatography is often performed with ion-exchange resinsto separate mineral salts, sugars and organic acids. The eluent is an aqueous solution whose $\mathrm{pH}$ can be adjusted with the inorganic acid or base corresponding to the counter-ions fixed on the resin so as to keep itscomposition constant. The separation of compounds is based on affinity differences for the resins. Higher is the affinity, slower migrates the compound along the resin bed.Inthe sugar industry, cationic resins are used to separate sucrose from saltsas well as sugars from each other. The glucose-fructose separation is among the most famous applications of preparative chromatography.Otherwise, anionic resins are performedfor the citric acid purification. Uptake and slowdown mechanisms are not well known and complex, coupling size exclusion, ligand exchange, hydrophilic or hydrophobic interactions and ion-exchange[1617].

In a previous work dealing with the purification of lactic, succinic and citric acids by chromatography with a strong anionic resin (quaternary ammonium), the Langmuir model fitted well with the experimental equilibrium isotherms obtained by frontal analysis[18]. However,the corresponding affinity coefficients were significantly lowerthan those obtained by pulse tests for succinic and citric acids. Their peaks had a singular tailing and were delayedcompared to simulated ones with the Langmuir model and experimental coefficients of isotherms. Indeed,the Langmuir model was insufficient to describe the organic acids retention on the strong anionic resin and frontal analysis gave underestimatedaffinity coefficients.

These results lead us to suspect the impact of conjugate bases (dissociated organic acids) retention by ion-exchange, despite their very low concentrations. Indeed, the citrate anion affinity is high for quaternary ammonium anionic resin according to selectivity coefficients given by resins producers. Usually, this uptake mechanism is not taken into account because the strong anionic resins are performed at such acid $\mathrm{pH}$ (1 to 1.5) that only 
dissociated.Thus, the organic acids dissociation is generally not consideredalthough such small amount of conjugate bases may have a significant impact if they are strongly retained.

The present work aimed at modelling uptake mechanisms on a strong anionic resin. The Langmuir model, commonly used for the retention of organic acids, was coupled with a usual ion-exchange model for the retention of conjugate bases. Simulation results were compared with experimental pulse tests to check the model. The final goalwas toimprove the accuracy of apreparative chromatographysimulation program in order to optimize the operating parameters of our pilot-scale ISMB unit (Improved Simulated Moving Bed).

\section{Chromatography modelling}

\subsection{Mass transfer model}

The Martin and Synge plate model [19] was chosen to describe the elution of organic acids through a strong anionic resin bed. In each plate of volume $\mathrm{V}$, the mobile phase takes up a volume $\varepsilon \bigvee$ and the stationary phase a volume $(1-\varepsilon) \bigvee$, with $\varepsilon$ the bed voidage. Usually, for preparative chromatography,volumes areexpressed in BV (bed volume)[20-22], corresponding to the ratio of volume to the resin bed volume.Both phases arealways supposed in equilibriumin all plates (nonlinear equilibrium in our case). The axial dispersion is characterized by the plate number $\mathrm{N}$.

\subsection{Uptakemechanisms- reactions in stationary phase}

The strong anionic resin is a styrene-divinylbenzene resin functionalized with quaternary ammonium groups $\mathrm{RMe}_{3} \mathrm{~N}^{+}$. The amount of these cationic sites corresponds to the ionexchange capacity $q_{R M e_{3} N^{+}}$of the resin, expressed in mol. $\mathrm{L}_{\text {resin }}^{-1}$. The resin is initially in the sulfate form, namely with thecounteranions $\mathrm{HSO}_{4}{ }^{-}$and $\mathrm{SO}_{4}{ }^{2-}$ in equilibrium. The proportion of both forms depends on their concentrationin the mobile phase, so on its $\mathrm{pH}$. The concentrations of hydroxyl anion $\mathrm{OH}^{-}$in both phases were considered negligible at $\mathrm{pH}<1.5$. 
1 The proposed model was based on two classical uptake mechanisms, with some

2 assumptions:

3

4

13

14

15

16

17

18
- Uptake of the organic acid in the dissociated form $\mathrm{A}^{-}$by ion-exchange with resin counteranions $\mathrm{HSO}_{4}{ }^{-}$and $\mathrm{SO}_{4}{ }^{2-}$.

- Retention of the organic acid in the molecular form $\mathrm{AH}$ according to the Langmuir model, by weak bonds (hydrogen or van der Waals), on free sites either on counteranions $\mathrm{HSO}_{4}{ }^{-}$and $\mathrm{SO}_{4}{ }^{2-}$ (weak nucleophiles, cf. UOP patents [23-24]) or on the polymer matrix whose capacity $q_{\text {mat }}$ is also expressed in mol. $\mathrm{L}_{\text {resin }}^{-1}$.We supposed that the $\mathrm{AH}$ retention does not modify the selectivity coefficients of counteranions.

Consequently, 6 compounds were considered in the stationary phase: $\mathrm{HSO}_{4}{ }^{-}, \mathrm{SO}_{4}{ }^{2-}, \mathrm{A}^{-}$, $\mathrm{AH}$-site $\left(\mathrm{HSO}_{4}^{-}\right), \mathrm{AH}$-site $\left(\mathrm{SO}_{4}{ }^{2-}\right)$ and $\mathrm{AH}$-site(matrix) (figure 1).

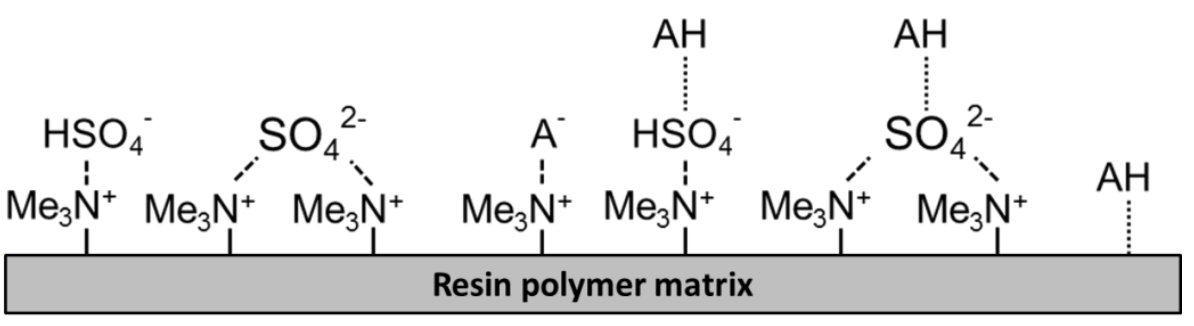

Figure 1- Illustration of the six compounds considered in the stationary phase

The ion-exchange reactions correspond to the following equilibria:

$$
\begin{gathered}
\left(R M e_{3} N^{+}\right)_{2} \mathrm{SO}_{4}^{2-}+2 A^{-} \leftrightarrow 2\left(R M e_{3} N^{+}\right) A^{-}+S_{4}^{2-} \\
\left(R M e_{3} N^{+}\right)_{2} \mathrm{SO}_{4}^{2-}+2 \mathrm{HSO}_{4}^{-} \leftrightarrow 2\left(R M e_{3} N^{+}\right) \mathrm{HSO}_{4}^{-}+\mathrm{SO}_{4}^{2-} \\
\left(R M e_{3} \mathrm{~N}^{+}\right) \mathrm{HSO}_{4}^{-}+A^{-} \leftrightarrow\left(R M e_{3} N^{+}\right) A^{-}+\mathrm{HSO}_{4}^{-}
\end{gathered}
$$

7 Sincethe affinity of counteranions $\mathrm{HSO}_{4}$ and $\mathrm{SO}_{4}{ }^{2}$ for resin cationic sites was supposed not influenced by $\mathrm{AH}$ uptake, theirequilibrium constants can be written as follows: 


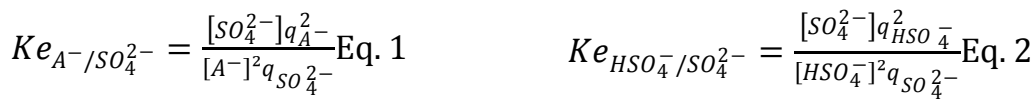

$$
\begin{aligned}
& \mathrm{Ke}_{\mathrm{A}^{-} / H S O_{4}^{-}}=\frac{\left[\mathrm{HSO}_{4}^{-}\right] q_{A^{-}}}{\left[A^{-}\right] q_{H S O_{4}^{-}}}=\sqrt{\frac{\mathrm{Ke}_{\mathrm{A}^{-}} / S O_{4}^{2-}}{\mathrm{Ke}_{\mathrm{HSO}}^{-} / S O_{4}^{2-}}} \text { Eq. } 3
\end{aligned}
$$

1 whereq $\mathrm{HSO}_{4}{ }_{4}$ andq $\mathrm{SO}_{4}^{2-}$ representthe $\mathrm{HSO}_{4}{ }^{-}$and $\mathrm{SO}_{4}{ }^{2-}$ contents inthe stationary phase (free or

2 bound to $A H), q_{A^{-}}$the $A^{-}$content and $[X]$ the concentration of $X$ in the mobile phase.

3 The ion-exchange equilibrium constants Kecan be estimated from data of resin

4 suppliersby equations 5-7. For example, the Dow Chemical Company gives the selectivity

5 coefficients of anions $\mathrm{X}^{-}$for a strong anionic resin in the hydroxide form, $k_{X / O H}$, defined as

6 follows:

$$
\begin{aligned}
& k_{X / O H}=\frac{q_{X}^{-}\left[\mathrm{OH}^{-}\right]}{\left[X^{-}\right] q_{O H^{-}}} \quad \text { Eq. } 4 \\
& \mathrm{Ke}_{\mathrm{HSO}_{4}^{-} / \mathrm{SO}_{4}^{2-}}=\frac{k_{\mathrm{HSO}_{4} / \mathrm{OH}}^{2}}{k_{\mathrm{SO}_{4} / \mathrm{OH}}} \quad \text { Eq. } 5 \quad \mathrm{Ke}_{\mathrm{A}^{-} / \mathrm{SO}_{4}^{2-}}=\frac{k_{\mathrm{A} / \mathrm{OH}}^{2}}{k_{\mathrm{SO}_{4} / \mathrm{OH}}} \quad \text { Eq. } 6 \quad \mathrm{Ke}_{\mathrm{A}^{-} / \mathrm{HSO}_{4}^{-}}=\frac{k_{\mathrm{A} / \mathrm{OH}}}{k_{\mathrm{HSO}_{4} / \mathrm{OH}}} \quad \text { Eq. } 7
\end{aligned}
$$

$7 \quad$ According to the Langmuir model, the $\mathrm{AH}$ uptake reactions on free sites on counteranions

$8 \mathrm{HSO}_{4}{ }^{-}$and $\mathrm{SO}_{4}{ }^{2-}$ and on the polymer matrix correspond to the following equilibria:

$$
\begin{gathered}
\text { Free } \mathrm{HSO}_{4}^{-} \text {site }+\mathrm{AH} \leftrightarrow \text { Occupied } \mathrm{HSO}_{4}^{-} \text {site } \\
\text { Free } \mathrm{SO}_{4}^{2-} \text { site }+\mathrm{AH} \leftrightarrow \text { Occupied } \mathrm{SO}_{4}^{2-} \text { site } \\
\text { Free matrix site }+\mathrm{AH} \leftrightarrow \text { Occupied matrix site }
\end{gathered}
$$

9 The corresponding equilibrium constants Ksare defined as follows:

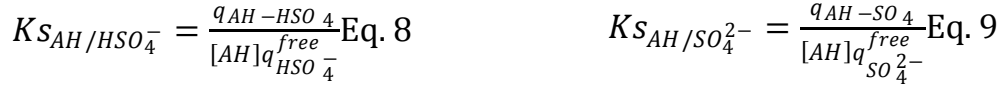

$$
\begin{aligned}
& K s_{A H / m a t}=\frac{q_{A H-\text { mat }}}{[A H] q_{\text {mat }}^{\text {free }}} \quad \text { Eq. } 10
\end{aligned}
$$


where $q_{\mathrm{AH}-\mathrm{HSO}_{4}}, q_{\mathrm{AH}-\mathrm{SO}_{4}}$ and $q_{\mathrm{AH}-\mathrm{mat}}$ represent the $\mathrm{AH}$ concentrations bound touptake sites

2 respectively on counteranions $\mathrm{HSO}_{4}{ }^{-}$and $\mathrm{SO}_{4}{ }^{2-}$ and on the polymer matrix, meanwhile $q_{\mathrm{HSO}_{4}{ }_{4} \text {, }}^{\text {free }}$

$3 q_{\mathrm{SO}_{4}^{2-}}^{\text {free }}$ and $q_{\mathrm{mat}}^{\text {free }}$ represent the concentrations of corresponding free uptake sites.

$4 \quad$ Mass balances on the three kinds of uptake siteslead to the followingequations:

$$
\begin{gathered}
q_{\mathrm{HSO}_{4}^{-}}^{\text {free }}=x q_{\mathrm{HSO}_{4}^{-}}-q_{\mathrm{AH}-\mathrm{HSO} \mathrm{O}_{4}} \text { Eq. } 11 \quad q_{\mathrm{SO}_{4}^{2-}}^{\text {free }}=y q_{\mathrm{SO}_{4}^{2-}}-q_{\mathrm{AH}-\mathrm{SO}_{4}} \text { Eq. } 12 \\
q_{\text {mat }}^{\text {free }}=q_{\text {mat }}-q_{\mathrm{AH}-\text { mat }} \quad \text { Eq. } 13
\end{gathered}
$$

5 where $\mathrm{x}$ and $\mathrm{y}$ correspond to the uptake capacity of counteranions $\mathrm{HSO}_{4}{ }^{-}$and $\mathrm{SO}_{4}{ }^{2-}$,

6 namely the number ofmolecule that can be retained per counteranion. Indeed, we assumed

7 that several molecules can eventually be retained on each counteranion. These numbers are

8 not necessarily integers and can be smaller than 1 if one molecule $\mathrm{AH}$ occupies several

9 counteranions $\mathrm{HSO}_{4}{ }^{-}$or $\mathrm{SO}_{4}{ }^{2-}$ for steric reasons.

For each type of uptake sites, the combination of one mass balance with its corresponding equilibrium constant gives the following usual equations ofthe Langmuir model. They relate concentration of $\mathrm{AH}$ retained respectively on the three kind of sites to $\mathrm{AH}$ concentration in mobile phase and total concentration of corresponding sites.

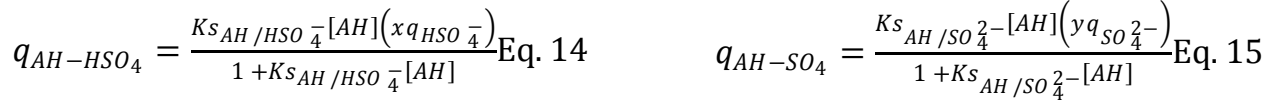

$$
\begin{aligned}
& q_{A H-m a t}=\frac{K s_{A H / m a t}[A H] q_{m a t}}{1+K s_{A H / m a t}[A H]} \quad \text { Eq. } 16
\end{aligned}
$$

\subsection{Reactions in mobile phase}

At low $\mathrm{pH}(<1.5)$, organic acids are mainly in themolecular form $\mathrm{AH}$, howeverthe retention of the dissociated form $A^{-}$was studied(for polyacids like succinic or citric acids, only the monodissociated formwas considered). So 5 species were considered in the mobile phase: 
$1 \mathrm{H}^{+}, \mathrm{HSO}_{4}^{-}, \mathrm{SO}_{4}{ }^{2-}, \mathrm{AH}$ and $\mathrm{A}^{-}$. The main reactions are both acid-base equilibria, whose

2 equilibrium constantsKa are defined as follows:

$$
\begin{aligned}
& \mathrm{AH} \leftrightarrow \mathrm{A}^{-}+\mathrm{H}^{+} \quad \mathrm{HSO}_{4}^{-} \leftrightarrow \mathrm{SO}_{4}^{2-}+\mathrm{H}^{+} \\
& \mathrm{Ka}_{\mathrm{AH}}=\frac{\left[\mathrm{A}^{-}\right]\left[\mathrm{H}^{+}\right]}{[\mathrm{AH}]} \quad \text { Eq. } 17 \quad \mathrm{Ka}_{\mathrm{HSO}_{4}^{-}}=\frac{\left[\mathrm{SO}_{4}^{2-}\right]\left[\mathrm{H}^{+}\right]}{\left[\mathrm{HSO}_{4}^{-}\right]} \quad \text { Eq. } 18
\end{aligned}
$$

3 The pKa of lactic, succinic and citric acids and hydrogen sulfate at $60^{\circ} \mathrm{C}$ (operating

4 temperature) are respectively 3.86, 4.13, 3.05 and 2.39.

5

6

\subsection{Plate mass balances}

$7 \quad$ The plate content is represented by 11 unknown variables ( 5 in the mobile phase and 6 in

8 the stationary phase) that obey 7 independent equilibrium relations (Eq. 1-2 and 14-18).

9 Consequently, 4 mass balancesare necessary to solve the system and estimate the content

10 of eachplate at time " $t$ " from the composition of all platesat time"t-1".

11 Mass balance of ion-exchange site $\mathrm{RMe}_{3} \mathrm{~N}^{+}$whatever the time $t$,

$$
2 \mathrm{q}_{\mathrm{SO}_{4}^{2-}}{ }_{\mathrm{t}}^{\mathrm{n}}+\mathrm{q}_{\mathrm{HSO}}{ }_{4}^{-{ }_{\mathrm{t}}}+\mathrm{q}_{\mathrm{A}^{-}}^{-\mathrm{n}}=q_{\mathrm{RM}_{3} N^{+}} \quad \text { Eq. } 19
$$

12 Mass balance of sulfate group $\mathrm{SO}_{4}$ between $t-1$ and $t$ :

$$
\begin{gathered}
\varepsilon V\left(\frac{\mathrm{d}\left[\mathrm{HSO}_{4}^{-}\right]_{\mathrm{t}}^{\mathrm{n}}}{\mathrm{dt}}+\frac{\mathrm{d}\left[\mathrm{SO}_{4}^{2-}\right]_{\mathrm{t}}^{\mathrm{n}}}{\mathrm{dt}}\right)+(1-\varepsilon) \mathrm{V}\left(\frac{\mathrm{dq}_{\mathrm{SO}_{4}^{2-}}{ }^{\mathrm{n}} \mathrm{t}}{\mathrm{dt}}+\frac{\mathrm{dq}_{\mathrm{HSO}_{4}^{-}}{ }^{\mathrm{n}}}{\mathrm{dt}}\right) \\
=\mathrm{Q}\left(\left[\mathrm{HSO}_{4}^{-}\right]_{\mathrm{t}}^{\mathrm{n}-1}-\left[\mathrm{HSO}_{4}^{-}\right]_{\mathrm{t}}^{\mathrm{n}}\right)+\mathrm{Q}\left(\left[\mathrm{SO}_{4}^{2-}\right]_{\mathrm{t}}^{\mathrm{n}-1}-\left[\mathrm{SO}_{4}^{2-}\right]_{\mathrm{t}}^{\mathrm{n}}\right)
\end{gathered}
$$

13 Mass balance ofacids ( $H^{+}$element) between $t-1$ and $t$ (water dissociation negligible):

$$
\begin{aligned}
& \varepsilon V\left(\frac{\mathrm{d}\left[\mathrm{H}^{+}\right]_{t}^{\mathrm{n}}}{\mathrm{dt}}+\frac{\mathrm{d}\left[\mathrm{HSO}_{4}^{-}\right]_{\mathrm{t}}^{\mathrm{n}}}{\mathrm{dt}}+\frac{\mathrm{d}[\mathrm{AH}]_{\mathrm{t}}^{\mathrm{n}}}{\mathrm{dt}}\right)+(1-\varepsilon) \mathrm{V}\left(\frac{\mathrm{dq}_{\mathrm{HSO}^{-}}^{-{ }_{4}}{ }_{\mathrm{t}}^{\mathrm{n}}}{\mathrm{dt}}+\frac{\mathrm{dq}_{\mathrm{AH}-\mathrm{HSO}_{4}}^{\mathrm{n}}{ }_{\mathrm{t}}^{\mathrm{n}}}{\mathrm{dt}}+\frac{\mathrm{dq}_{\mathrm{AH}-\mathrm{SO}_{4}}{ }_{4}^{\mathrm{n}}}{\mathrm{dt}}+\frac{\mathrm{dq}_{\mathrm{AH}-\mathrm{mat}_{\mathrm{t}}}^{\mathrm{n}}}{\mathrm{dt}}\right) \\
& =\mathrm{Q}\left(\left[\mathrm{H}^{+}\right]_{\mathrm{t}}^{\mathrm{n}-1}-\left[\mathrm{H}^{+}\right]_{\mathrm{t}}^{\mathrm{n}}\right)+\mathrm{Q}\left(\left[\mathrm{HSO}_{4}^{-}\right]_{\mathrm{t}}^{\mathrm{n}-1}-\left[\mathrm{HSO}_{4}^{-}\right]_{\mathrm{t}}^{\mathrm{n}}\right)+\mathrm{Q}\left([\mathrm{AH}]_{\mathrm{t}}^{\mathrm{n}-1}-[\mathrm{AH}]_{\mathrm{t}}^{\mathrm{n}}\right)
\end{aligned}
$$




$$
\begin{gathered}
\varepsilon V\left(\frac{\mathrm{d}\left[\mathrm{A}^{-}\right]_{\mathrm{t}}^{\mathrm{n}}}{\mathrm{dt}}+\frac{\mathrm{d}[\mathrm{AH}]_{\mathrm{t}}^{\mathrm{n}}}{\mathrm{dt}}\right)+(1-\varepsilon) \mathrm{V}\left(\frac{\mathrm{dq}_{\mathrm{A}^{-}}^{-\mathrm{n}}}{\mathrm{dt}}+\frac{\mathrm{dq}_{\mathrm{AH}-\mathrm{HSO}_{4}}^{\mathrm{n}}}{\mathrm{dt}}+\frac{\mathrm{dq}_{\mathrm{AH}-\mathrm{SO}_{4}{ }_{4}}^{\mathrm{n}}}{\mathrm{dt}}+\frac{\mathrm{dq}_{\mathrm{AH}-\mathrm{mat}_{\mathrm{t}}}^{\mathrm{n}}}{\mathrm{dt}}\right) \\
=\mathrm{Q}\left(\left[\mathrm{A}^{-}\right]_{\mathrm{t}}^{\mathrm{n}-1}-\left[\mathrm{A}^{-}\right]_{\mathrm{t}}^{\mathrm{n}}\right)+\mathrm{Q}\left([\mathrm{AH}]_{\mathrm{t}}^{\mathrm{n}-1}-[\mathrm{AH}]_{\mathrm{t}}^{\mathrm{n}}\right)
\end{gathered}
$$

In the last three mass balances, the terms on the left-hand side of the equal sign correspond respectivelyto the accumulation terms in the mobile phase and in the stationary phase, meanwhile the expressionson the right-hand side correspond to the difference between inputs (fromthe $(n-1)^{\text {th }}$ plate) and outputs (from the $n^{\text {th }}$ plate).Q represents the flowrate.

The proposed model depends on 10 parameterswhose value is more or less known accuratelyaccording to data from resin suppliers, literature or our own experimental results:

- Plate number: $\mathrm{N}$,

- Resin ion-exchangecapacity: $q_{R M e_{3} N^{+}}$expressed in mol. $\mathrm{L}_{\mathrm{resin}}^{-1}$,

- Polymer matrix uptake capacity: $q_{m a t}$ expressed in mol. $\mathrm{L}_{\text {resin }}^{-1}$,

1 - $\mathrm{HSO}_{4}^{-}$uptake capacity: $x$,

2 - $\mathrm{SO}_{4}{ }^{2-}$ uptake capacity:y,

- Equilibrium constant of ion-exchange between $\mathrm{A}^{-}$and $\mathrm{HSO}_{4}^{-}: \mathrm{Ke}_{\mathrm{A}^{-}} / \mathrm{HSO}_{4}^{-}$,

- Equilibrium constant of ion-exchange between $\mathrm{A}^{-}$and $\mathrm{SO}_{4}{ }^{2-}: \mathrm{Ke}_{\mathrm{HSO}_{4}}{ }_{4} / \mathrm{SO}_{4}^{2-}$,

5 - Equilibrium constant of $\mathrm{AH}$ uptake onHSO${ }_{4}^{-}$counteranions: $\mathrm{Ks}_{\mathrm{AH} / \mathrm{HSO}_{4}}$,

6 - Equilibrium constant of $\mathrm{AH}$ uptake on $\mathrm{SO}_{4}{ }^{2-}$ counteranions: $\mathrm{Ks}_{\mathrm{AH} / \mathrm{SO}_{4}{ }^{2-} \text {, }}$

7 - Equilibrium constant of $\mathrm{AH}$ uptake onresin polymer matrix: $\mathrm{Ks}_{\mathrm{AH} / \mathrm{mat}}$.

\subsection{Numerical methods}

The finite-difference method with implicit schemewas used to discretize the 3 differential equations (eq. 20-22). The Newton-Raphson iterative methodwas chosen to solve the nonlinearsystem of 4 remaining equations after simplification. The model and its numerical solving were computed using the software MATLAB ${ }^{\circledR}$. The initial conditions (concentrations in 
1 both phases) need to be givenas well as the boundary conditions: compositionof the feed

2 (organic acid solution then eluent) as a function of time.

3

4

11

\section{Results and discussion}

\subsection{Simulation withonly the Langmuir model andcoefficients of equilibrium isotherms}

First, the simulations of organic acids elution through a strong anionic resin bed were performedconsidering that $\mathrm{AH}$ was only retained on the polymer matrix, according to the Langmuir model.We used the coefficients of equilibrium isotherms obtained previously by frontal analysis (table 1). So, the elution profiles were only influenced by 3 parameters: the plate number $\mathrm{N}$, the polymer matrix uptake capacity $q_{\text {mat }}$ equated to $q_{\max }$ and the equilibrium constant of $\mathrm{AH}$ uptake on resin polymer matrix $\mathrm{Ks}_{\mathrm{AH} / \mathrm{mat}}$ equated to $K s_{A H}$.

Table 1- Resin uptake capacity $q_{\max }$ and equilibrium constant $K s_{A H}$ of 3 organic acids estimated by frontal analysis at $60^{\circ} \mathrm{C}$ for a strong anionic resin [18]

\begin{tabular}{ccc}
\cline { 2 - 3 } & $\boldsymbol{q}_{\max }$ & $\boldsymbol{K \boldsymbol { s } _ { \boldsymbol { A H } }}$ \\
& mol. L $_{\text {resin }}^{-1}$ & $10^{-1} L_{\text {solution }} \cdot \mathrm{mol}^{-1}$ \\
\hline Lacticacid & $6.8 \pm 2.6$ & $1.4 \pm 0.5$ \\
Succinicacid & $2.7 \pm 0.9$ & $7.2 \pm 2.5$ \\
Citricacid & $2.5 \pm 0.2$ & $9.0 \pm 1.7$ \\
\hline
\end{tabular}

For lactic and succinic acids, the resin uptake capacity $q_{\max }$ and the equilibrium constant $K s_{A H}$ have significant error margin because it was not possible to get enough experimental points in the nonlinear region of equilibrium isotherms [18].

According to our previous study[18], the plate number Nwas set to250for the 3 organic acids. It corresponds to the experimental value obtained by pulse testswith lactic acid whose symmetric profile is the most appropriate to characterize axial dispersion. The plate number $\mathrm{N}$ 
1 was considered equal for all species. Indeed, the study of axial dispersion (Van Deemter

2 curves) in this work showed that the molecular diffusion is negligible compared to the

3 mechanical dispersion and the influence of mass transfer limitation, which were quite similar

4 between compounds in our experimental operating conditions.

5 These conditions were appliedin the model so as to compare with experimental results:

$60.05 \mathrm{BV}$ of $60 \mathrm{~g} . \mathrm{L}^{-1}$ organic acid solution, whose $\mathrm{pH}$ was adjusted to 1.4 with sulfuric acid,

7 were eluted with a $2.5 \mathrm{~g} \cdot \mathrm{L}^{-1}$ sulfuric acid solution. The temperature was $60^{\circ} \mathrm{C}$ and the flow

8 rate was $0.5 \mathrm{BV} \cdot \mathrm{h}^{-1}$.

9 For lactic acid, the simulation results are quite close to the experimental ones (figure 2).

10 So, the lactic acid uptake mechanisms by a strong anionic resin can be well fitted with only

11 the Langmuir model. However, this model is insufficient to simulateelution of succinic and

12 citric acids. Indeed, the simulation gives much earlier and narrower peaks than the

13 experiments, particularly for citric acid.Another uptake mechanism must then be responsible

14 for the delay and peak tailingobserved experimentally and should be taken into account.

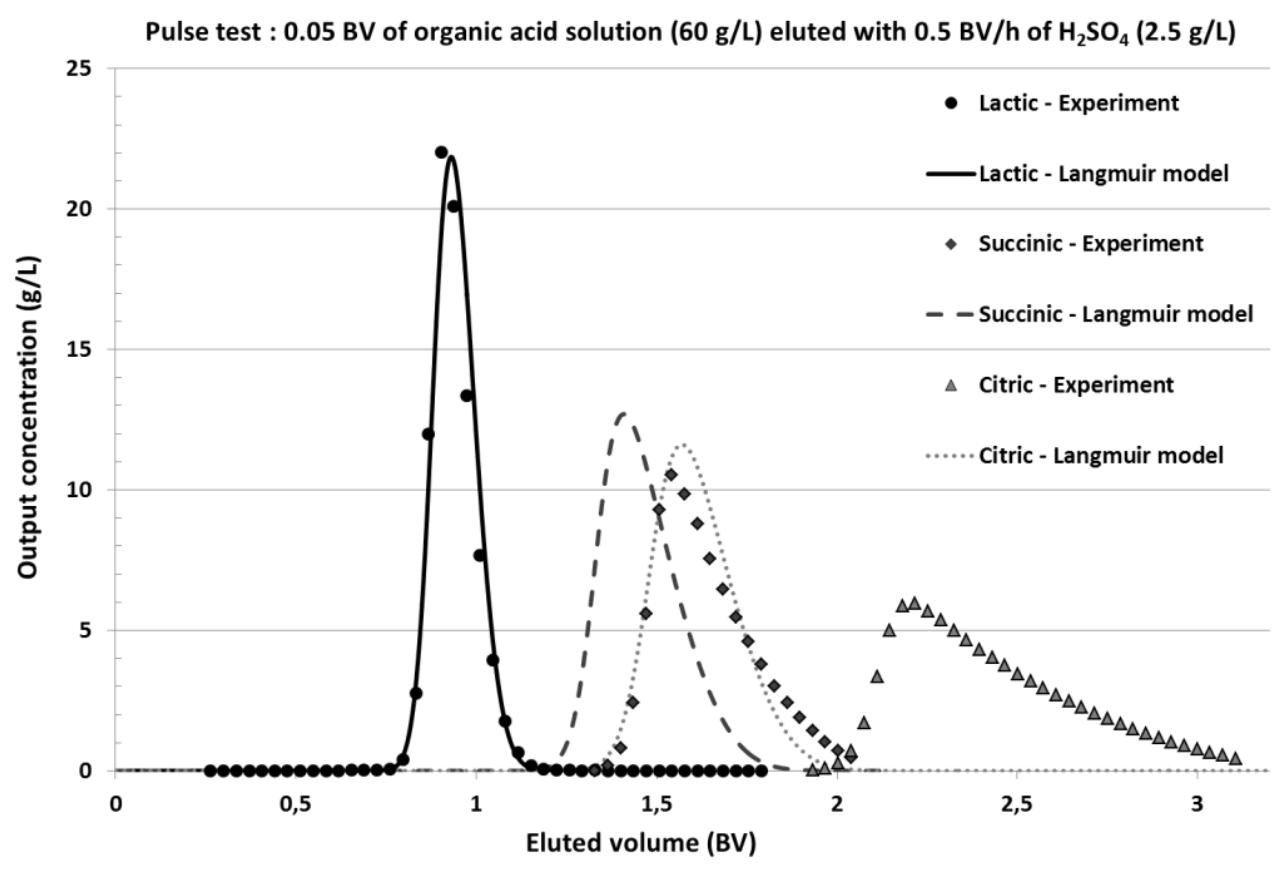


Simulations of organic acids elution were performed with the proposed model which takes into accountthe retention of the molecular form $\mathrm{AH}$ according to the Langmuir model and the retention of the dissociated form $A^{-}$by ion-exchange with resin counteranions.

To simplify, as a start, we considered that the molecular form $\mathrm{AH}$ was retained only on free uptake sites ofcounteranions $\mathrm{HSO}_{4}{ }^{-}$and $\mathrm{SO}_{4}{ }^{2-}$ according to UOP patents [23-24]. Moreover, we supposed that the equilibrium constants of $\mathrm{AH}$ uptake on both counteranions were equal. They were estimated first from the experimental equilibrium constant $K s_{A H}$ (table 1), then optimized by fitting simulation results to experimental profiles (least squares method). They were expected lower than $K s_{A H}$ since it includes also the contribution of ionexchange in retention.

According to the supplier, the ion-exchange capacity $q_{R M e_{3} N^{+}}$is about1.35mol. $\mathrm{L}_{\text {bed }}^{-1}$, equivalent to $2.4 \mathrm{~mol}$. $\mathrm{L}_{\text {resin }}^{-1}$. The uptake capacities of counteranions $\mathrm{HSO}_{4}{ }^{-}$and $\mathrm{SO}_{4}{ }^{2-}$, $x$ and $y$,were supposed equal and defined fromthe experimental uptake capacity $q_{\max }$ (table 1). For instance, $q_{\max }$ of lactic acid is twofold to threefoldhigher than $q_{R M e_{3} N^{+}}$, so $x$ and $y$ were supposed equal to 2 (table 3). It could be related to both nucleophile carbonyl groups of counteranions $\mathrm{HSO}_{4}{ }^{-}$and $\mathrm{SO}_{4}{ }^{2-}$ while lactic acid gets only one electrophile hydroxyl group. It means that 2 molecules of lactic acid can be retained on each counteranion.For succinic and citric acids, $x$ and $y$ were supposed equal to 1 (table 3 ). squares method). 
Table 2- Selectivity coefficients of some anions (compared with $\mathrm{OH}^{-}$) on a strong anionic resin

(Data from Dow Chemical Company)

\begin{tabular}{ccccccc}
\hline & $\mathrm{HSO}_{4}{ }^{-}$ & $\mathrm{SO}_{4}{ }^{2-}$ & Citrate $^{*}$ & Formate & Acetate & Propionate \\
$\mathbf{k}_{\mathbf{X} / \mathbf{O H}}$ & 85 & 150 & 220 & 4.6 & 3.2 & 2.6 \\
\hline \multicolumn{5}{c}{ * Valence not mentioned }
\end{tabular}

4

5 The plate number $\mathrm{N}$ was still set to 250 for the 3 organic acids. Values of simulation

6 parameters for the 3 organic acids were gathered in the table 3 .

7

Table 3 - Optimized parameters for simulation of lactic, succinic and citric acids elution with the proposed model which also takes into account Äion-exchange

\begin{tabular}{|c|c|c|c|c|}
\hline & & & & \multirow{2}{*}{ Citricacid } \\
\hline & & Lacticacid & Succinicacid & \\
\hline $\bar{N}$ & $\overline{-}$ & 250 & 250 & 250 \\
\hline$q_{R M e_{3} N^{+}}$ & mol. $L_{\text {resin }}^{-1}$ & 2.4 & 2.4 & 2.4 \\
\hline $\boldsymbol{k}_{\mathrm{A} / \mathrm{OH}}$ & - & 2.5 & 330 & 110 \\
\hline $\boldsymbol{k}_{\mathrm{HSO}_{4} / \mathrm{OH}}$ & - & 85 & 85 & 85 \\
\hline$k_{S O_{4} / O H}$ & $L_{\text {resin }} \cdot L_{\text {solution }}^{-1}$ & 150 & 150 & 150 \\
\hline$K s_{A H / H S O_{4}^{-}}$ & $L_{\text {solution }} \cdot \mathrm{mol}^{-1}$ & 0.225 & 0.82 & 0.70 \\
\hline$K s_{A H / S o_{4}^{2-}}$ & $L_{\text {solution }} \cdot \mathrm{mol}^{-1}$ & 0.225 & 0.82 & 0.70 \\
\hline$x$ & - & 2 & 1 & 1 \\
\hline$y$ & - & 2 & 1 & 1 \\
\hline
\end{tabular}

11 The figure 3 shows that the proposed model fitted very well the experimental profiles with 12 coherent value for each parameter compared to experimental and resin supplier'sdata.The 13 delay and peak tailing observed mainly withsuccinic and citric acids can be reproduced with 14 this model. 


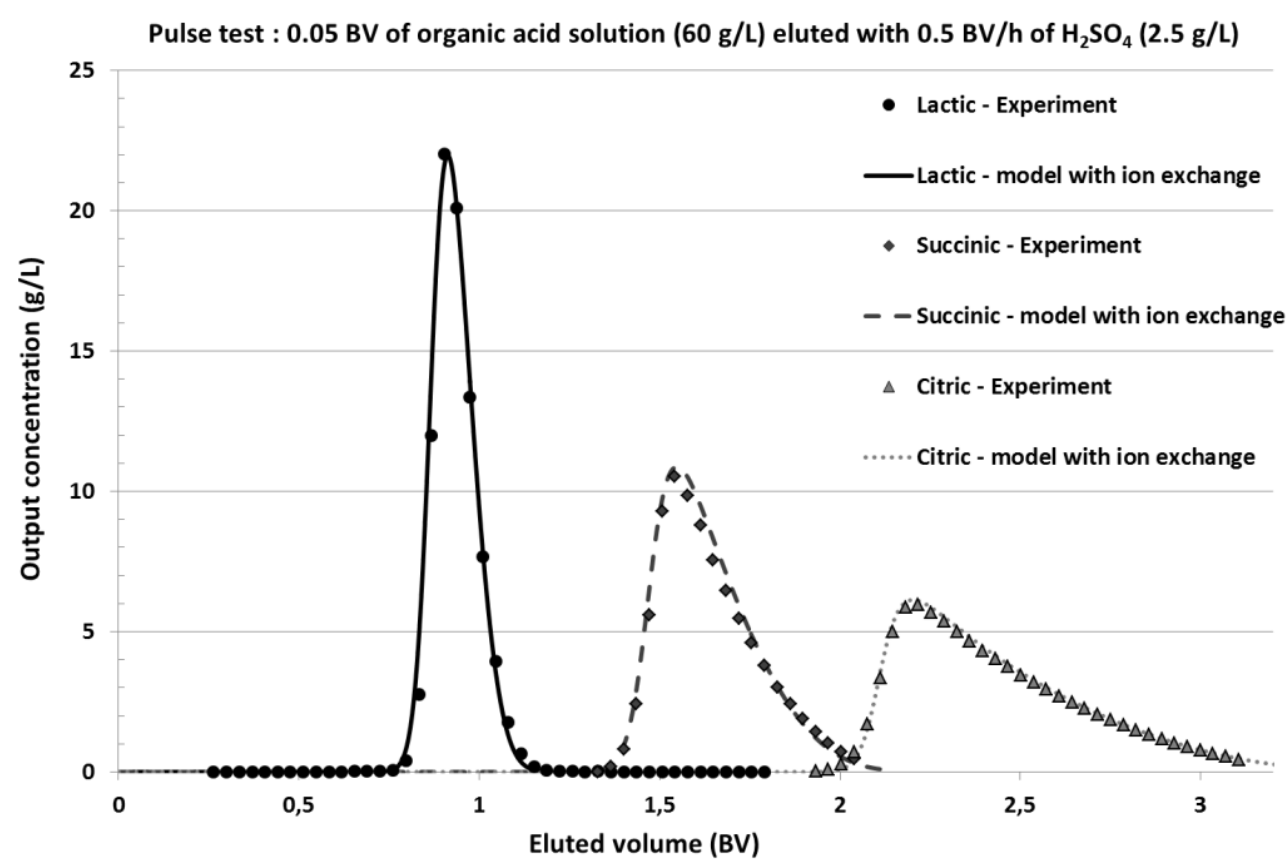

Figure 3 - Comparison of experimental pulse test profiles and simulations ones consideringthe Langmuir model combined with ion-exchange of conjugate bases

It confirms that the retention of the dissociated organic acids by ion-exchange with resin counteranions must be considered despite of the very lowdissociation of the acid at acidic $\mathrm{pH}$ $(0.1$ to $2 \%)$. Indeed, the conjugate base of some organic acids, like citrate, can have a very

high affinity for resin cationic sites, so the organic acid can be much moreretained than expected. Moreover, it shows that assumptions added in this simulation to simplify the model wereacceptable.

\subsection{Implementation in a ISMB chromatography simulation program}

This uptake model was developed in order to improve simulation of preparative chromatography like ISMB (Improved Simulated Moving Bed) that is currently used at pilot scale in our laboratory. We aimed at predicting the ISMB performance more accurately with strong anionic resins and optimizing operating parameters according to thewanted recovery rates and purities. 
An ISMB unit is composed of 4 columns in series filled with the stationary phase. The

2 ISMB process consists in changing sequentially position of inputs (feed and eluent) and

3 outputs (extract enriched with the more retained component, succinic acid, and raffinate

4 enriched with the less retained, salts and lactic acid). An operating step is composed of four

5 different sub-steps, where each column corresponds to one zone:

1) Feed input in the zone 3 and raffinate output from the zone 3.

2) Eluent input in the zone 1 and extract output from the zone 1.

3) Eluent input in the zone 1 and raffinate output from the zone 3.

4) Recirculation loop with all zonesconnected in series.

After one step, each zone is shifted by one column: the zone 1 becomes the zone 2,the zone 2 becomes the zone 3, etc. So, a cycle is performed after 4 steps. ISMB performance depends on different volumes eluted during these four sub-steps.

ISMB simulations were performed with the Langmuir model whose coefficients were optimized previously from an experimental pulse test at pilot scale, then with the model developed whose coefficients were also optimized in the same way. The feed was mainly composed of sulfatesalts (16 g/L), succinic acid $(65 \mathrm{~g} / \mathrm{L})$ and lactic acid $(14 \mathrm{~g} / \mathrm{L})$ while the eluent was a $2.5 \mathrm{~g} / \mathrm{L}$ sulfuric acid solution.

The figure 4 shows that the proposed model fitted better ISMB experimental profiles than the Langmuir model. The accuracy of ISMB simulation with strong anionic resin was improved by taking into account the retention of dissociated organic acids by ion-exchange, 21 despite their very low concentrations. 


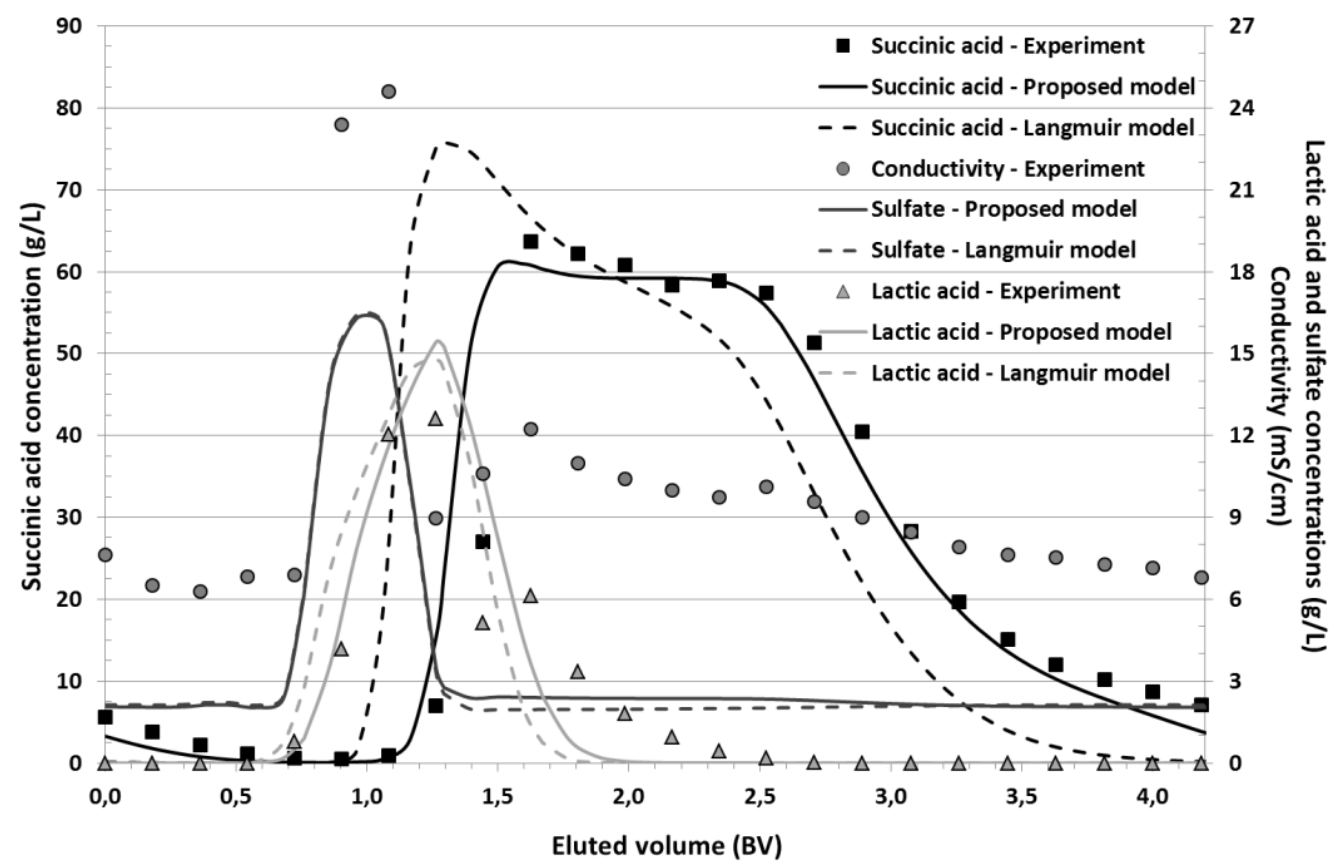

Figure 4 - Comparison of experimental ISMB profiles with simulated ones, first with the model which is developed, then with the Langmuir model only

\section{Conclusion}

Preparative chromatography is an efficient separation technique which is spreading in different industrial fields. For several years now, anionic resins have been performed for the citric acid purification, however uptake mechanisms are still not well known. In a previous work [18], peaks corresponding to succinic and citric acids exhibited singular tailing and delay which could not be explained only by the Langmuir model.

The uptake mechanisms supposed in the proposed model are relevant to explain the characteristic elution profiles of some organic acids obtained in pulse tests. To sum up, we assume that the acid molecular form can be retained on resin counteranions or polymer matrix while the dissociated form can be fixed to cationic sites by ion-exchange. Usually, the organic acids dissociation is not considered at such low $\mathrm{pH}(<1.5)$, but we proved that even a very small proportion of dissociated form can have a significant impact when it is strongly retained. This is the reason why the Langmuir model is sufficient for lactic acid because of 
1 the low affinity of lactate but insufficient for citric acid since citrate affinity is very high for

2 quaternary ammonium anionic resins.

3 The developed model was implemented in a preparative chromatography (ISMB)

4 simulation program in order to optimize the operating parameters of our pilot-scale unit and

5 improve estimation of its performance. Experimental ISMB profiles confirmed that the

6 proposed model was better than the Langmuir model to describe the organic acids retention

7 on strong anionic resins.

8 Next, a plug flow reactor model will be used to take into account different axial dispersions

9 of compounds. Moreover, it would be interesting to further investigate so as to support the

10 assumptions which were made to simplify the model and eventually to refine it.

\section{Acknowledgements}

12 The authors would like to thank the Fondation Paris-Reims, the RégionChampagne-

13 Ardenne, the Département de la Marne and ReimsMétropole for their financial support. 


\section{References}

2 [1] National Renewable Energy Laboratory, Top value added chemicals from biomass, vol. I, 2004.

3 [2] Sauer M, Porro D, Mattanovich D andBranduardi P, Microbial production of organic acids:

4 expanding the markets, Trends Biotechnol. 26 (2008) 100-108.

5 http://dx.doi.org/10.1016/j.tibtech.2007.11.006

6 [3] Dierdorp BM, Groot WJ, Van BJ and Veldhuis-Stribos BI,Continuous process for preparing lactic acid, WO Patent 0127064 A1, 2001.

8 [4] JoglekarHG, Rahman I, Babu S, Kulkarni BD and Joshi A, Comparative assessment of

9 downstream processing options for lactic acid, Sep.Purif. Technol. 52 (2006) 1-17. http://dx.doi.org/10.1016/i.seppur.2006.03.015

11 [5] Sterzel HJ, Vogel H, Exner H and DetlefKratz, Preparation of lactates, US Patent 5453365, 1995.

[6] Sun X, Wang Q, Zhao W, Ma H and Sakata K, Extraction and purification of lactic acid from

13 fermentation broth by esterification and hydrolysis method, Sep.Purif. Technol. 49 (2006) 43-48.

$14 \quad$ http://dx.doi.org/10.1016/i.seppur.2005.08.005

[7] Kumar R, Mahajani SM, Nanavati $\mathrm{H}$ and Noronha SB, Recovery of lactic acid by batch reactive distillation, J. Chem. Technol.Biotechnol. 81 (2006) 1141-1150.

17 http://dx.doi.org/10.1002/jctb.1444

[8] Coszach P, Bogaert JC, Mariage PA, Chianese A and Parisi MP, Method for purifying lactic acid by crystallization, WO Patent 072473 A1,2010.

[9] Huh YS, Jun YS, Hong YK, Song H, Lee SY and Hong WH, Effective purificationofsuccinicacidfromfermentationbrothproducedby Mannheimiasucciniciproducens, Process Biochem. 41 (2006)1461-1465.

[10] Guiochon G, Preparative liquid chromatography, J.Chromatogr. A 965 (2002) 129-161. http://dx.doi.org/10.1016/S0021-9673(01)01471-6

26 [11] MolnárZ, Nagy M, Aranyi A, Hanák L, Argyelán J, Pencz I andSzánya T, Separation of amino acids with simulated moving bed chromatography, J. Chromatogr. A 1075 (2005) 77-86. 
2 [12] llisz I, Aranyi A, Pataj Z and Péter A, Enantiomeric separation of nonproteinogenic amino acids

3 by high-performance liquid chromatography, J. Chromatogr. A 1269 (2012) 94-121.

$4 \quad$ http://dx.doi.org/10.1016/j.chroma.2012.07.011

5 [13] Kumar V,Leweke S, von LieresE andRathore AS, Mechanistic modeling of ion-exchange process

6 chromatography of charge variants of monoclonal antibody products, J. Chromatogr. A 1426 (2015)

$7 \quad 140-153$.

$8 \quad$ http://dx.doi.org/10.1016/j.chroma.2015.11.062

9 [14] Guélat B,Khalaf R, Lattuada M, Costioliand Morbidelli M, Protein adsorption on ion exchange resins and monoclonal antibody charge variant modulation, J. Chromatogr. A 1447 (2016) 82-91.

$11 \quad$ http://dx.doi.org/10.1016/j.chroma.2016.04.018

[15] Huh YS, Jun YS, Hong YK, Song H, Lee SY and Hong WH, Fructose-glucose separation in a

13 SMB pilot unit: Modeling, simulation, design, and operation, AIChE J. 47 (2001) 2042-2051.

14 http://dx.doi.org/10.1002/aic.690470915

[16] Stefansson $M$ andWesterlund D,Ligand-exchangechromatographyof carbohydrates and glycoconjugates, J.Chromatogr. A 720 (1996) 127-136. http://dx.doi.org/10.1016/0021-9673(95)00276-6

[17] Nobre C, Santos MJ, Dominguez A, Torres D, Rocha O, Peres AM, Rocha I, Ferreira EC,

Teixeira JA and Rodrigues LR, Comparison of adsorption equilibrium of fructose, glucose and sucrose on potassium gel-type and macroporous sodium ion-exchange resins, Anal.Chim.Acta 654 (2009) 7176.

http://dx.doi.org/10.1016/i.aca.2009.06.043

[18] Blanc CL, Theoleyre MA, Lutin F, Pareau D andStambouli M, Purification of organic acids by chromatography: adsorption isotherms and impact of elution flow rate, Sep.Purif. Technol. 141(2015) 105-112. http://dx.doi.org/10.1016/i.seppur.2014.11.032

27 [19] Guiochon G,Shirazi DG, Felinger A andKatti AM, Fundamentals of Preparative and Nonlinear 28 Chromatography, Academic Press (2006) 283-286. ISBN 0123705371,9780123705372 
1 [20] Thang VH andNovalin S, Green biorefinery: separation of lactic acid from grass silage juice by

2 chromatography using neutral polymeric resin, Bioresour. Technol. 99(2008) 4368-4379.

3 http://dx.doi.org/10.1016/j.biortech.2007.08.045

4 [21] Wu J, Hu Y, Zhou J, Qian W, Lin X, Chen Y, Chen X, Xie J, Bai J and Ying H, Separation of d-

5 lactic acid from aqueous solutions based on the adsorption technology, Colloids

6 Surf.Physicochem.Eng.Asp.407 (2012) 29-37.

7 http://dx.doi.org/10.1016/..colsurfa.2012.04.051

8 [22] Morin-Couallier E, Fargues C, Lewandowski R, Decloux M andLameloise ML, Reducing water

9 consumption in beet distilleries by recycling the condensates to the fermentation phase, J. Clean.

10 Prod. 16 (2008) 655-663.

11 http://dx.doi.org/10.1016/j.jclepro.2007.02.009

12 [23] Kulprathipanja S andOroskar AR, Separation of lactic acid from fermentation broth with an

13 anionic polymeric absorbent, US Patent 5068418 (1991).

14 [24] Kulprathipanja S and Oroskar AR, Separation of an organic acid from fermentation broth with an 15 anionic polymeric adsorbent, US Patent 5068419 (1991). 